\title{
Beyond Bricks and Mortar: The efficacy of online learning and community-building at College Park Academy during the COVID-19 pandemic
}

\author{
Kate Maloney Williams ${ }^{1}$ D $\cdot$ Anne Corwith ${ }^{1}$ id
}

Received: 1 February 2021 / Accepted: 22 March 2021 / Published online: 31 March 2021

(C) The Author(s), under exclusive licence to Springer Science+Business Media, LLC, part of Springer Nature 2021

\begin{abstract}
In March 2020, COVID-19 appeared in the State of Maryland, resulting in strict stayat-home orders and the shutting down of physical business operations. These restrictions directly impacted College Park Academy (CPA), a public charter middle and high school in Prince George's County, MD that typically follows a hybrid approach to in-person and online instruction. The purpose of this qualitative study was to review CPA's transition to full online distance learning during emergency remote teaching. The research worked to establish a snapshot of the school's underlying structure and disaster preparedness strategies before evaluating the perceived viability of the online model and its effects on students, teachers, parents, and educational administrators. The researchers conducted interviews, as well as document analysis and online classroom observations. The findings reveal that despite strong infrastructure and communications during the transition, there remained issues with school readiness, including the maintenance of academic rigor and social emotional wellbeing. Overall, recommendations are made as to how the school would benefit from a shift in its approach to technology-enhanced learning, including the need for digital tools that better facilitate wellness checks, provide human touchpoints, and target collaborative, student-centered pedagogy. These lessons learned are relevant for other school administrators to consider as society continues to adapt to a new era of virtual learning during times of crisis.
\end{abstract}

Keywords Disaster risk reduction · Online distance learning · Social emotional learning · COVID-19 · Qualitative methods · Community of Inquiry

Kate Maloney Williams

kmwills@umd.edu

Anne Corwith

anne.s.corwith@gmail.com

1 College of Education, University of Maryland, College Park, College Park, MD, USA 


\section{Introduction}

The timeline of crisis response is hard to define. Studies show that the full life cycle of a disaster averages up to 20 years and that the longer children are out of school the more difficult it is for them to return (UNHCR, 2016a; UNHCR, 2016b). Apart from economic development and personal wellbeing, education helps a country's citizens develop resiliency to handle future crises, teaching students skills to identify risks and prepare for disasters (Gaillard et al., 2018; Reyes, 2013; Winthrop \& Matsui, 2013). Guidance varies at different international, national, and local levels on how school systems should prepare for and respond to crises.

In March 2020, COVID-19 appeared in the State of Maryland, resulting in strict stayat-home orders and the shutting down of physical business operations for offices and schools. These orders directly impacted College Park Academy (CPA), a public charter middle and high school in Prince George's County, founded by the University of Maryland and the City of College Park. Since opening its doors in 2013, CPA has offered a unique approach to "hybrid learning," offering traditional core academic courses in-person and other enrichment, elective, and educational support courses virtually via Pearson Connexus, an online course management system (CMS). In response to stay-at-home orders, the school adopted district policies that transitioned lessons to full online delivery, limiting teaching hours from 9:00 a.m. to 1:00 p.m., only holding one subject per day, and designating grades for the remaining school year to Pass/Incomplete. CPA leadership anticipated that this transition would be efficient and successful, given its established platform and the requirement for all students to have computer access at home.

This interpretative qualitative case study was originally commissioned by CPA to better understand the school's successes in adapting to a fully virtual environment, including the maintenance of quality educational delivery. It was to serve as a postmortem for best practices and lessons learned with the hope that the findings could be shared out as an exemplar to other school districts. The primary research questions included 1) what factors within the CPA model allowed the school to transition smoothly to full online delivery, 2) what challenges did teachers and staff face in its implementation, and 3) what were the satisfaction levels with educational quality and delivery by students and families? The findings reveal that despite the pre-COVID hybrid model and a strong communications campaign during the transition there remained issues with school readiness, including the maintenance of academic rigor and social emotional well-being during the acute stage of emergency remote teaching. These lessons learned are relevant for other school administrators to consider as society continues to adapt to a new era of virtual learning during times of crisis.

\section{Conceptual framing}

\subsection{Disaster response and recovery for education}

For this study, we utilized guidance issued by UNESCO's International Institute for Education Policy (IIEP-UNESCO, 2020a) and the Inter-agency Network for Education in Emergencies (INEE, 2020). Both highlighted two main points to ensure the 
continued provision of education during the pandemic recognizing inherent overlap in response and recovery phases:

1) Maintain Operational Capacities During School Closures by ensuring continuity that is flexible, accessible, inclusive, and gender-responsive (IIEP-UNESCO, 2020b).

2) Provide continuous support to teachers, learners, and their families. Psychosocial support and social emotional learning of students and staff should be appropriate, effective, and ongoing (IIEP-UNESCO, 2020c).

These two aspects of pandemic response are also represented by the U.S. Department of Education's (ED) Readiness and Emergency Management for Schools (REMS) approach, which outlines four areas of recovery to address: 1) Academic, 2) Physical and Structural, 3) Business Functions, 4) and Social, Emotional, and Behavioral (REMS TA Center, 2006).

\subsubsection{Maintaining operational capacity}

Recommendations for maintaining operational capacity during pandemics indicate that disaster and emergency response should be built upon already existing disaster preparedness plans, which includes differing levels of response (e.g., the responsibility of communicating and collaborating with the state and local health departments). As schooling is firstly centered on learning, the continued provision of academics is key to any response to a crisis.

Physical and structural recovery of the school buildings, facilities, supplies, and equipment is necessary to provide a learning environment. In the case of the pandemic response, the school building and facilities were not directly impacted. However, ensuring teachers, students, staff, and administrators have the equipment and supplies necessary to support distance education and school administration is paramount. Business functions recovery is ensuring the continuation of the administrative functions of the school, such as the human resource functions of hiring, payroll, and contracts; registrar functions of class registration, academic assessment, and promotion; and the provision of child safety and welfare.

\subsubsection{Provide continuous support}

Schooling is intertwined with the social, emotional, and behavioral growth and wellbeing of its students and is also key to the psychological and emotional wellbeing of teachers and staff. The impact of a crisis disrupts the stability and established support mechanisms available to children and may result in withdrawal, anti-social behavior, and apathy towards schoolwork and academic progress (Gaillard et al., 2018; REMS TA Center, 2006). Disaster preparedness literature speaks to disaster risk reduction and resilience as focused at the local level, such that all stakeholders be included in these efforts (Hyogo Framework, 2005; Sendai Framework, 2015). In disaster risk literature, the term Child Centered Risk Reduction should be considered 
when developing and implementing response plans. Considering the unique capabilities that children have in recognizing and recovering from disasters, it is important to include them in their own recovery and further develops their resiliency (Gaillard et al., 2018). As CPA's response to the pandemic did not involve significant impact to the school facilities or structure, this study simplified the REMS Framework into three areas of exploration: Academics, Business Functions/Infrastructure, and Social and Behavioral.

Additionally, for Academics, we recognize that distance learning creates unique challenges in identifying what constitutes excellence in educational delivery. In this regard, our investigation included accounting for the quality of learning and instruction during emergency remote teaching. By and large, there are several features that constrain online learning, including the type of setting, the nature of the content, and the technology involved (U.S. Department of Education, 2010). Media Ecology Theory (MET) takes into consideration the interplay of these mediated encounters within a classroom environment. From there, the Community of Inquiry (COI) Framework and Universal Design for Learning (UDL) principles were applied to explore the quality of the educational experience.

\section{Literature review}

\subsection{Media Ecology Theory (MET)}

Edward T. Hall once wrote that "in studying man it is impossible to separate the individual from the environment in which he functions" (Hall, 1976, p. 100). It is under this world view that media ecology is the theoretical study of how media, technology, and communication affect human environments, including school systems.

An integral idea is the recognition that media does not just revolve around analog technologies (i.e., television) or digital technologies (i.e., computers). Every utility - for example, a pencil, a paper, or chalkboard - is a medium, each one containing its own message. Media ecology's founding father, Marshall McLuhan (1964), once wrote that "our conventional response to all media, namely that it is how they are used that counts, is the numb stance of the technological idiot. For the 'content' of a medium is like the juicy piece of meat carried by the burglar to distract the watchdog of the mind" (p. 31).

According to media ecology, media are ubiquitous, determine what we know and how we feel about what we know, and connect us to others. These ideas are never more salient than applied to an online classroom and a virtual experience. It is important to remember that the classroom serves as media environment in and of itself. It is the architecture of a medium-how it is designed and built - that affects the constraints faced by a user. It is through this code that behavior can be constrained by making other behaviors possible or impossible. As development communications expert, Nora Quebral (1988), wrote:

a curriculum, educationists tell us, is more than the constituent courses. It is also the teaching methods, the course materials and aids, the facilities, and 
in truth the entire experience that the students undergo in the learning environment. All of these components embody values that consciously or unconsciously shape the learners. (p. 53)

Further, the social web (or "Web 2.0") allows educators to rethink the Internet as a traditional transmission model or broadcast channel. Generative websites and social media platforms help to redefine power dynamics in creativity, production, and learning (Gauntlett, 2011). To this end, 21st Century Skills, such as problem solving, collaboration, and creation, need to be fostered by classrooms, so that students grow up to have the functional and critical skills needed to engage as both digital citizens and workers and navigate their mediated lives.

\subsubsection{Community of Inquiry Framework (COI)}

The Community of Inquiry (COI) Framework (Garrison et al., 2000) is a social constructivist model of learning used for assessing both online and blended learning environments. It is essentially defined by three dimensions: 1) Teaching presence, 2) Social presence, and 3) Cognitive presence. It holds that through this intersection a meaningful educational experience occurs. Under these dimensions, "teaching presence" refers to the ways in which instructors design their syllabi, course objectives, and methods. It is the extent to which a teacher is accessible by the students. In other words, how hands-on they may be with the teaching and feedback, how easy it is for students to communicate with them, and how invested students feel that the teacher is to themselves and their learning successes. More specifically, "social presence" involves the extent to which students feel connected to their peers in an online environment and the extent to which they feel that they are perceived as "real people."

Generally, online misbehavior can be driven by the extent to which the Internet offers anonymity (Sternberg, 2012) and is applicable to student behavior in a virtual learning environment. In the online classroom, if students are not perceived as people, this can lead to less accountability, retention, or engagement. For example, it is often one of the main reasons that Massive Open Online Classrooms (MOOCs) are seen to fail (Hone \& El Said, 2016). To address these challenges, COI upholds that online classrooms require open communication, affective expression, and group cohesion (or "teambuilding") as the groundwork for fostering deep learning and student engagement. "Cognitive presence" ties directly into theories on digital authorship; it is the extent to which students are given the opportunity to construct and make meaning through continued reflection and discourse.

As ED (2010) notes, "modern online learning includes offerings that run the gamut from conventional didactic lectures or textbook-like information delivered over the Web to Internet-based collaborative role-playing in social simulations and highly interactive multiplayer strategy games" (p. 3). COI takes into consideration the type of learning experience, which can be defined through the amount of control that the student has over content and the nature of the learning activity. Rather than traditional didactic or expository learning experiences (i.e., transmission models, banking models, rote learning), technologies better afford for both active and interactive learning. Under these structures, an active learner builds knowledge 
through inquiry-based exploration of digital production. Technology is intended as the mediator for human interaction with real learning hinging on those generative activities. In turn, this works to redefine the role of teachers as co-learners, facilitators, or "guides" to learning (Fischer, 2011; Lee \& Tan, 2018; McWilliam, 2009).

According to ED (2010), "the learner-control category of interactive learning experiences is related to the so-called "fifth generation" of distance learning, which stresses a flexible combination of independent and group learning activities" (p. 4). "Distributed learning" or "learning communities" refer to these combinations of synchronous and asynchronous exchanges over an extended period of time. This also includes the extent to which activities fall into either category.

The current study also positions critical thinking as both a process and an outcome. A central pillar in defining a Community of Inquiry is cognitive presence or "the acquisition of deep and meaningful understanding as well as content-specific critical inquiry abilities, skills, and dispositions" (U.S. Department of Education, 2010). In the words of Unwin (2009), “'knowledge' requires higher-order human processing, whereas 'information' is something that is generally only produced and communicated" (p. 21). With the shift to virtual learning, the simplification of content, paired with interactive multimodal activities, is important for ensuring student engagement and cognitive processing.

\subsection{Universal Design for Learning (UDL)}

Over the years, the COI concepts informed instructional design guidance, such as Universal Design for Learning (UDL) (CAST, 2018). UDL supports the neurological argument that good design helps students with self-motivation in their learning. Comprehensively, it holds that educational systems can serve specific goals and objectives, such as equity, diversity, and flexibility, by proactive design. It aims to reduce barriers in instruction through an intentional and systematic delivery, striving to circumvent the need for individual accommodation. In this way, the idea is that no one is isolated or left behind.

Online classroom spaces, particularly vis-à-vis course management systems, provide their own set of challenges and affordances towards structuring a meaningful, interactive, and inclusive learning environment. To this end, UDL takes on its own approach specific to this medium and its usability. Evidence has shown that "thoughtfully designed online instruction has proven to enhance a learner's engagement with the course material, the instructor, and with one another" (Hollingshead \& Carr-Chellman, 2019, n.p.). Although there are generally seven principles that UDL utilizes, these are framed by three overlying concepts - that online classrooms must provide 1) multiple means of representation, 2) multiple means of expression, and 3) multiple means of engagement.

Fundamentally, each one of us as learners vary in the ways we perceive and comprehend information, whether or not it is related to any underlying sensory or learning disabilities, as well as language or cultural differences. An online course should be designed to allow students to receive content through multiple modes of expression - video, audio, text, activities, discussion, and assessment. This 
includes offering final products seeped in digital authorship rather than just exams or papers. Students have some autonomy and license in creating final products that utilize different forms of multimedia, often in ways that typical classrooms would not quite be able to do. All learners differ in the ways we are able to navigate an online classroom and effectively share what we know. An online classroom needs to be designed from the beginning to be scaffolded, navigable, and conceptually demonstrated.

\section{Research design}

\subsection{Research methods}

According to Unwin (2009), "deciding whether or not something is truly revolutionary depends on the criteria that one selects for analysis, and on the extent to which one is willing to acknowledge the significance of antecedents in shaping the phenomenon under investigation" (p. 20-21). Since the research focus was on CPA's transition to distance learning specifically during the pandemic, the research team followed a traditional case study methodology. As Merriam (2002) writes, the case study is an intensive description and analysis of a single entity or unity that attempts to describe a phenomenon in-depth; it is "the unit of analysis, not the topic of investigation, [that] characterizes a case study" (p. 8). Further, when researching an environment that contains multiple physical, sociological, and psychological variables, such as a school community, there is not one method that can be truly comprehensive. Rather, in the spirit of trying to encompass a holistic understanding and be in a position to make critical, interpretative evaluations, it requires the triangulation of different data sources.

Our research team conducted semi-structured interviews with school community members, document analysis, and online classroom observations. The interviews centered on capturing participants' perceptions and lived experiences. Observations included live and archived classroom instruction, as well as attending the virtual Parent Teacher Association and Townhall meetings. The research team also reviewed key documents that included the Faculty and Staff Handbook, Parent and Student Handbook, and the CPA Academy website.

The REMS TA Four Components of Recovery served as the basis for the development of the interview protocols. Within the Academics component, the three dimensions of COI to address Cognitive, Teaching, and Social presence in the distance learning setting were embedded in the interview protocols and served as the basis for the Observation protocols.

An invitation to participate in the case study was emailed to CPA leadership, administrators, teachers, parents, students, and support personnel in both English and Spanish. Participants must have been engaged with the school starting August 2019 at the earliest and planned to remain engaged with the school until June 12, 2020. All protocols were approved by Institutional Review Board. 


\subsection{Data collection}

Due to the pandemic, all communications and research were conducted virtually. Interested participants were screened and categorized by profile group for oneon-one virtual interviews: teacher, administrator, student, parent, and key personnel. Ultimately, 17 interviews were conducted with three administrators, two staff members, two parents, five teachers, and five students. These interviews lasted from 30-90 minutes. Based on participants' consent, the Research Team either audio and/ or video recorded the interviews.

The research team also conducted observations within Connexus, attending LiveLessons and reviewing archived recordings. No individual identifiable information was recorded. However, general observations on communication strategies, curriculum delivery, and student and teacher interactions and engagement were collected.

In order to minimize potential open-endedness, data analysis techniques relied heavily on detailed organization and mutual agreement on thematic coding, including the co-development of an agreed upon coding framework. The research team followed the approach recommended by Corbin \& Strauss (2015), "before beginning to code, we read the entire interview, field note, or document as well as view the video, resisting the urge to do any analysis at this time" (p. 86). Throughout research design, data collection, and reflection, the team created an audit trail using checklists and annotations to analyze interview transcripts, field notes, and documents. These measures facilitated the coding process and supportive use of NVivo software.

\section{Analysis and findings}

\subsection{Academics}

The role of Connexus in existing content delivery greatly assisted CPA in transitioning to full distance learning. As one parent remarked:

[The students have] dealt with the Connexus platform for a really long time, and they're very used to going in and accessing all of their materials online instead of being given a packet or something else. I think that it was really, really helpful for them because all of the troubleshooting and all the things that other students would have to get used to.

However, data showed notable issues concerning the limitations of the online platform and the teachers' need to incorporate other technologies. Primarily, Connexus did not allow for attaining the types of social and teacher presence proposed by COI. This was largely fueled by the design of the platform but may also have been impacted by individual teachers' skills and general level of comfort with distance learning methods.

Although the hallmark of a quality CMS is its ability to integrate a range of tools into a single source login, there did not appear to be a vast repertoire of such extensions within Connexus. During several observations, teachers supplemented direct 
instruction with links to other websites to help foster engagement among students. For example, one teacher referenced a shared Google Doc for note-taking and collaborative study support. Other platforms teachers reported using included DeltaMath, Pear Deck, Google Classroom, Kahoot, and Quizlet, but they also appeared to be used limitedly.

Further, observation of LiveLessons demonstrated instructional deliveries that were entirely one-way communication. One teacher attempted to explain this dynamic stating:

The shift that I noticed was all of a sudden I was back to that lecture style. Whereas when we're in the classroom, I can break [the students] into small groups, and I can have them make posters and present to each other, or I can have them jigsaw a project together, but with the platform limitations, and then, of course, the physical separation, it was more of me leaning back on [lecture].

Despite CPA's capacity for building from the established Connexus platform, district-based policies also worked to lock teachers into a solely lecture-based format. For one, PGCPS established a required schedule for delivery of core content, which limited instruction to one content area per day for each day of the week. Additionally, PGCPS policies did not allow for students to be on camera during live-streamed lessons. Students remarked on how these policies impacted the overall learning environment.

Middle School Student: Well, for us in Connexus -- when we first switched, it was basically just like doing homework, but for all the classes in the entire day, we would have one LiveLesson for a single class each week, and it felt a lot different from that perspective. We would only have 45 minutes to learn stuff, and the teacher would try and cram as much information into our heads during that time, and I felt like I didn't learn as much because of that.

On the one hand, this may have been partially mitigated by the Pass/Incomplete Policy set by PGCPS. However, administrators felt that the policy demotivated students who already achieved passing grades.

\subsection{Business/Infrastructure}

Although the school facilities and structure were not impacted per se, students, teachers, and administrators were confronted with stringent stay-at-home orders requiring not only the continuity of academics through distance learning but the overall administration of the school as well. The administrators and teachers tapped into the knowledge and planning for other disasters, yet the pandemic highlighted issues that were new to ensuring all students maintained access to continued learning and teachers and administrators were able to continue their work remotely from home. 


\subsubsection{Existing technology tools and policies}

The physical and structural aspects of maintaining continuity meant that families, teachers, staff, and administrators had to have the necessary equipment and Internet access at home. The existing hybrid learning structure of CPA and its requirement that all students have computer access provided the school a head start to the transition to complete distance learning. In addition, CPA maintained a selection of loaner laptops for students to use if their personal computers were no longer viable.

The transition to distance learning required flexibility in terms of academic policies, scheduling, and promotion. Although there is existing and constant tension between the vision of CPA, the policies and requirements of PGCPS, and the Prince George's County Educators' Association (PGCEA), the strength and experience of existing relationships among the leadership of CPA, PGCPS, and PGCEA helped CPA navigate the policies imposed upon it in response to the pandemic. CPA was able to submit waivers for certain policies which were either turned down or granted.

\subsubsection{Technology requirements}

Although CPA had an already established Internet platform for curriculum and virtual learning, other management platforms were needed to help support the school administration's transition to complete distance education and school community support, requiring additional training and some financial investment. Some platforms were systems already used by PGCPS, such as SchoolMax. SchoolMax is described as a Family Access Portal that allows caregivers to see student information, such as class registration, attendance, and assignment scores. The SchoolMax robocall system was heavily utilized with messages being sent practically every day as it was one of the main ways to communicate with the school community.

Administrator: We also use a robocall system, which we have email, text, phone of every single parent member, staff member, administrative member of our school community in one system, and we're able to send out all of that type of correspondence. Even though we used that before, I would say that we're sending out a robocall message every day now just because it's our only way to communicate.

Furthermore, the guidance counselors utilized two PGCPS required systems. The first, Naviance, is a college and career planning platform, which, as the guidance counselor stated, has "mandatory tests every grade level has to do." By utilizing Connexus LiveLesson, the guidance counselors provided students instructions on how to $\log$ into Naviance and complete the tests. The guidance counselor also received training on Doxy.me, a confidential Internet platform that is HIPAA compliant in case any personal counseling sessions were needed. However, the nature of both the privacy infrastructure and professional usages required by these mechanisms mandates that they stay housed separately. Although this is largely done in the name of user protections, it does fracture user interactions requiring that staff and families maintain access to multiple accounts besides Connexus. 
Even though CPA's curriculum was supported by Connexus, the school needed to purchase additional LiveLesson licenses from Pearson's Connect for its core teaching staff. Teachers and staff received training over the April Spring Break, giving up vacation time to learn how to use the functionality as well as expand their abilities with the communication systems available, such as the Connexus announcement system and webmail.

Staff Member: They call it LiveLesson. I didn't even know, I had to learn, I had to be trained. As I know some other teachers did too because they never used that feature, they didn't need to. Even though the curriculum was online, they were in class teaching like any other school.

The pandemic offered a unique opportunity for the guidance counselor to use the Connexus platform to create web pages and LiveLessons regarding Naviance and counseling service information. The only downside the guidance counselor spoke to was that she had to copy and paste the information into the parental portal:

It feels like my own home webpage. I have all the links to any of the forms that they might need or information or anything that came up for a scholarship opportunity. All this and all my LiveLessons were recorded, and they're on there so students can go back and watch them, just like a teacher's page. This pandemic has created this wonderful opportunity for me now to have a place that I know students can get used to going to for counseling services, for all those questions they have, graduation requirements, service learning, testing requirements, any kind of scholarships that come up for seniors.

\subsubsection{Accessibility}

One aspect school administrators, teachers, and families did not anticipate was that everyone would need to access the Internet from home concurrently, causing issues with household bandwidth. Although participants did not initially indicate issues with Internet access, as interviews dug deeper, access-related challenges did emerge. For example, one participant indicated it took close to two months to have a Digital Subscriber Line (DSL) upgrade installed as a service person would not come to the house due to the pandemic:

Parent: Everybody on it was lagging. People were getting cut off, which couldn't load screens, and we couldn't even get it upgraded because nobody could come into the house. It was a huge ordeal. We finally were able to get it upgraded and that was a huge help. Turns out we had a really low speed, lower than-- they don't even offer it anymore.

Others mentioned that the bandwidth was slow, especially when multiple users were online at the same time. Considering there may be multiple Internet users in a household, the ability to access recorded lessons at different times when other members of the household did not have to be online was seen as a plus. As a teacher commented, "I think that that's one of the really good things 
too about our LiveLessons, is in archiving all of them, so that the students can go back if they are experiencing [technology] issues." Yet, students' inability to engage fully in synchronous classes reduced the level and quality of online social presence.

\subsubsection{Work space}

For the most part, participants, students, staff, teachers, parents, and administrators all indicated that it was not too hard to find conducive work space at home. Parents indicated that they "made it work" with children studying at the kitchen or dining room table or in their rooms. There were a few comments that, at times, it was challenging with different voices or conversations ongoing. As one parent said:

The space was okay. It was a matter of when they were in LiveLessons. If they were all on at the same time, it was just too much noise because this person's talking to their teacher over here, and this person talking to their teacher over here, and it was too much.

Although students who were only-children consistently did not acknowledge privacy issues, those with siblings did admit to challenges:

Middle School Student: [I don't have a private work space] because when I'm in my room, sometimes, my little brothers, they come in here and make noise or start playing around and stuff. That bothers me.

High School Student: Since you're at home, there's a lot more to distract you. At first, I used to think that CPA really could just be done at home, that there's no need to come into school. You realize if you don't have a specific place where you can do at least some organized learning even if it's for 30 minutes a day, there's just a lot that distracts you. There's always something that you have to do like pets you have to take care of, chores you have to do, being called on by family, people coming in when you're in a class, in a virtual class, just things like that going on.

Additionally, administrators, teachers, staff, and students all commented on missing being "in the building." Staff mentioned they were more productive in the office and found it difficult to be motivated working from home.

Staff Member: I prefer to work in the office. I work better in the office. This is just for me personally. I watched my work ethic decrease, which is crazy because if you ask any of the other ladies that work in the front office, I'm a workaholic.

\subsubsection{Communication}

Overwhelmingly, participants felt that the school administrators provided consistent, timely, direct communications. Existing communication systems were utilized, such as the SchoolMax robocalls and newsletter. In addition, the administrators organized 
four Townhalls conducted on Zoom utilizing an account available from a parent employed by the University of Maryland that allowed for up to 1,000 participants. These Townhalls were highly attended by parents, teachers, and some staff members. The Townhall agenda was sent out by robocall, and parents were provided time to ask questions through the chat function. For questions not answered during the meeting, the staff and teachers prepared a document with the questions and answers to send out to parents after the Townhall meeting through the SchoolMax robocall system and posted on the CPA website. As one administrator stated:

We're really just inundating our community with information, but before we would inundate them, we would try to make it as succinct as possible so that it was edible for people, and they could take it in and understand what we were talking about.

Staff and faculty meetings continued online per their regular schedules and staff commented on how the continuation of the crowdsourced Coffee Corner electronic newsletter contributed to a sense of consistency and stability. Communication channels between PGCPS, the Board, University of Maryland and other external stakeholders were well-established through personal and longterm contacts and, as reported by participants, was open and collaborative. Parents and staff also commented on how the school administrators were extremely responsive to their questions and concerns, particularly receiving responses quicker than they had anticipated. Overall, participants responded how the consistency and continuity of communications were beneficial to creating a sense of stability and normalcy,

Challenges that arose with communication consisted of parents not familiar with how to communicate with teachers through Connexus. One parent described troubleshooting sending emails via Connexus through her children's profiles. Other parents removed their own personal email addresses from Connexus, limiting its capacity for facilitated email-based communications between teachers and caregivers. Although Connexus maintained an internal communication system, most parents appeared to favor convenience and familiarity of use, opting to use external communication channels. This compounded issues regarding secure communication. For example, since district rules limit the use of students' access to external emails, other workarounds had to be found. Without school-based phones, teachers expressed concerns at having to use their personal phone numbers but, in some cases, employed Google Voice for communicating with parents. In general, most school-based communications underscored wide-ranging tensions between facilitating access and safeguarding for security purposes.

\subsection{Social and behavioral}

\subsubsection{Proactive and reactive approaches to Social and Emotional Learning (SEL) support}

The third area of focus of the REMS framework is to sustain the psychological and emotional wellbeing of the CPA community members as well as support the 
continued social, emotional, and behavioral growth of its students. The research findings showed an unexpected duality in CPA's collective school response. In support of parents, teachers, and other school staff, it was clear that the transition was made easier by a strong proactive focus on communications and that dissemination on this front was well-executed. This was felt through breadth, frequency, and variety of message delivery. As mentioned, town halls, robocalls, emails, etc. led to many adults (parents, teachers, and administrators) feeling supported and a part of a well-connected community. One parent expressed that these calls were not just abundant but had a level of much needed personability during the strained time of social distancing:

[The administrators] were very available. Like I said, there was constant, I say robocalls, but it wasn't even a robot. It was [the principal]. It's not like the other schools when we had that one lady that always said it. It was him, and he was always there to answer questions through email or phone calls.

Similarly, teachers also expressed a high-level of interpersonal communication between their departments. It was also indicated that there was a lot of collaboration between the middle and high school teachers, particularly for the eighth to ninth grade transition. One middle school teacher stated that:

I feel really fortunate to work here. Even before distance learning, they [CPA] were always very accommodating with me potentially needing absences, or they always checked-in with me ... they were always making sure that I was doing okay. That didn't change with distance learning, the administration has always been very much like, 'Work your contract hours, don't overwork yourself, separate your personal life from your work life. If you need help, we're here to help you. Let us know what we can do.'

However, the data showed a disconnect between this type of approach and direct communications to the student body. For one, none of the student interviewees indicated that the school chose to engage students in community-based activities during the transition - whether that be increased digital training, disaster planning for the school, or more community-based activities, such as mask making, that would have made students feel better connected to others across their school and neighborhoods. Presumably, it might have been anticipated that through increased parental communications, a "trickle down" effect would reach and benefit the students. However, if more communications and community participation were geared directly to and engaged students during long-term distance learning (after hurried initial school closure), the model might have allowed for a better modeling of responsible and proactive adult behaviors. The onus was put on students to be their own advocates - not exactly recognizing the mixed levels of resiliency and emotional maturity demonstrated in adolescence. In turn, this left many students feeling like nobody genuinely cared about them during these uncertain and challenging times and that they were ultimately alone. Arguably, it takes even more resolve for teenagers to reach out for help when faced with a solely online environment, when there are only so many appropriate ways to 
articulate, send, and chase an email. Many ancillary platforms and digital tools that might have facilitated better or increased communications, such as backchannels or collaborative platforms, were not used. This is especially relevant in light of the decision to leave LiveLessons mostly anonymous for users in the interest of student privacy.

Several members of the teaching and support staff indicated that if students did not come to them, they presumed no major issues with social emotional wellbeing:

High School Teacher: My strength in teaching comes from my ability to develop relationships with the students and get to know them and have them buy-in to what they're good at or buy-in to what I'm selling. That's my thing, and that's a lot of face-to-face, checking in, how's your family, like 'what's going on with soccer?' All the things that I now can't do unless they show up for office hours.

High School Teacher: My feeling was because I didn't have any students that I was particularly worried about, if I wasn't hearing from them, my assumption was, they're fine. They're turning in their work, they're showing up to the LiveLesson. I didn't see any evidence or get any emails from someone who was distraught.

High School Teacher: The students who reach out to me ... I wouldn't even mark them late under normal circumstances because they're being adult and professional enough to let me know what's going on with them to get ahead of being late. The ones I mark later are the ones that have no excuse, don't offer me an excuse, and just show up and hand me something late.

Middle School Teacher: You can sometimes try to figure it out like, 'Oh, this person hasn't submitted everything, and they usually are like on top of it, maybe I should check-in,' but there wasn't much else to be able to check-in on the kids.

These quotations reveal an approach that is in direct contrast to that taken with the adults in the school community - one that is reactive. These words also show several shortcomings towards supporting the vulnerabilities of young students and equity within those divides. The notion by the one teacher that there is no way to gauge student wellbeing unless they were to show up to office hours does not demonstrate a solid comfort-level with digital pedagogy. Those comments also are centered on emergency remote teaching and do not provide a view towards a more longterm distance learning solution. For example, how much responsibility does that teacher take on for establishing rapport with students if the start of the new school year is only online? There are several strategies that can foster human touchpoints, but these capabilities ideally need to be afforded by the platform itself. The research study observations revealed that Connexus as a platform did not allow much space for generative and reciprocal exchange, strictly featuring audio-visual content and lecture as its focal point. Additionally, although a teacher toolkit for assessing student SEL existed at CPA, it was eliminated when district rules prohibited the viewing of students in lessons.

As UDL literature demonstrates, reactive approaches are not typically best suited for online classroom environments, particularly for those with apparent or hidden special 
needs. When not designed with intention, the online classroom can quickly become a space that is impersonal, isolating, and non-interactive. Particularly, as College Park Academy takes a mixed - but siloed - approach to online and in-person delivery, the students found it to be very challenging to navigate what were formerly in-person classes. Largely, they felt that social presence and teacher presence, particularly responsiveness, were lacking and believed that because school staff did not reach out to them first, they simply did not care about them as individuals. Clearly, the teachers and counselors were waiting for the students to reach out first instead. In turn, this created a cycle of disengagement, where students did not want to reach out, mostly because they 1) felt that their messages went into a void, 2) did not know how to otherwise seek help, or 3) had not necessarily been shown healthy ways to express vulnerability.

For example, one middle school student spoke about how his mother contacted the counselor due to her concerns over his wellbeing. The counselor set up weekly meetings for him to join, but he saw the meetings as stigmatized, stating "I don't really need counseling to help me feel emotionally stable or stuff like that." In the time of COVID-19, students need all the support that they can get to process uncertainty whether they may overtly recognize fears and triggers themselves. While school counselors indicated that students really only sought them out for college admissions supports, high school interviewees clearly did not understand that the counselors were there for any other purpose and felt that they were entirely disinterested in them, aside from college admissions. This perspective may have been unwittingly impacted by the historical lack of a school counselor for the school's first four years, followed by school counselor turnover. However, better awareness and signposting can still be achieved.

High School Student: None of the guidance counselors at this school were ever supportive.

High School Student: [The guidance counselor] had these LiveLessons, but she would favor the students who are doing so well like with the 4.5 GPA or the 4.0. She would only cater to them because they had such a high GPA. If you had a 4.0 and below, she would just ignore you, leave you out. I think it's hard to explain.

High School Student: I remember when somebody did pass away at our school [from COVID-19] ... They just made it so awkward for the rest of the students. It's like they didn't care.

To be clear, this study is not accessing whether these claims are inherently true - nor is it judging the intentions of any CPA staff. However, it is crucial to point out the students' perceptions of social emotional support and the classroom during COVID-19. It was clear that the students interpreted the undertone from the school that class should be "business-as-usual" with many youth concerned that they could not focus on their homework due to "more important" and distracting things happening in the world. For example, one middle school student stated:

I sometimes get frustrated doing all the work that they sent us because me, personally, and other people I know, they think that during these times that doing homework isn't necessarily the thing that we should be doing right now. 
The lack of opportunity for student engagement in the school's disaster response and recovery plans and the school's reactive approach to communicating with students positioned the students as passive participants to the extraordinary circumstances impacting their lives and communities during this time.

\subsubsection{Student relationships and safeguarding capacity at a distance}

The disconnect was also aggravated by internalized attitudes demonstrated by both teachers and students. On the side of students, more than one said that they witnessed an increase in bullying, describing the cyberbullying that occurred as "hardcore" and likely emerging from other students' "boredom with distance learning." It was also indicated that bullying mostly occurred on student social media accounts, making it next to impossible for the school to have any means of appropriately identifying or addressing:

High School Student: I think, honestly, it [the online transition] made it [bullying] worse because the school can't tell me to, 'Oh, take your comment down, etc. [about] what you said about X, Y, Z.'

Although social media monitoring may be beyond most staff purview, the issue remains: what touchpoints can be harvested to promote relationship building, safeguarding, and conflict mediation with the online transition to full distance learning, especially strictly within a Connexus or Google Classroom environment?

One teacher expressed resentment over the requirement that teachers be responsible for reporting suspected child abuse as a part of their duties, stating that it was an unrealistic expectation and created tension in the parent-teacher relationship. However, he also raised a crucial problem, stating "I think the biggest thing that this COVID is going to expose within the school system is the realization that if teachers are not seeing that student every day, who is going to make those checks?" Similarly, another teacher commented:

There were a couple of kids that ended up contracting COVID, and I didn't know until I got an email a couple of weeks later from my principal telling me about that. That kind of thing was really hard for me because I couldn't see their faces because when you're with the kids all day, you can tell when their mood is just shifted a little bit or when they may not be feeling well, and I didn't have that in-person to be able to talk to them. I didn't see any of their faces in the LiveLessons.

Ultimately, the technology needs to facilitate the teachers being able to see the students, and the teachers may need some training on reading verbal and non-verbal cues and establishing social presence online, including strategies for discussion boards, digital authorship, or instant message chats. A given platform also needs to have enough multimodal affordances to facilitate these checks. One middle school teacher attempted to manage these checks herself, trying to carve out ad hoc strategies: 
When I was teaching in person, I always did like their warm-up sheets. I had WhatsApp Wednesday where they would just be able to say anything for extra credit. I put that into distance learning too where every Wednesday they would just be able to submit anything. Most of the time the kids just submitted memes or pictures of their pets and stuff like that to get the extra credit, which I was fine with. Some kids did use that as a way to tell me that they were struggling, but obviously, I'm sure that there were a lot of other kids that were struggling.

Additionally, students and staff alike commented on how much they appreciated even small, mindful gestures like the school-wide "motivational minute" announcements. One student stated that the announcements increased their focus, capacity to complete work, and just "helped a lot." This worked to mitigate the loss of in-person interactions but only limitedly. More so, educators complained over the loss of what can best be described as "backpack time," the informal space before and after class. To this end, school-led strategies for technology-facilitated touchpoints could prove hugely beneficial. The lack of social and teacher presence affordances are being directly seen as hurting morale. As one interviewee stated:

I truly believe, maybe it's because I'm a counselor, but the majority of people do thrive interacting actually in-person with other people. Yes, we can do Zooms. I'm seeing you, but it's not the same as if we were meeting in person, it's just not. I feel like there's been some students that have reached out to me that said they miss school and I'm like, 'What about school do you miss?' They never say the work. It's 'I miss seeing my friends. I miss actually being in a room with my teacher and learning that way.'

In the interviews, many teachers and support staff assumed that students would be using phone calls and Zoom more to stay in touch with their friends. However, this was not indicated by the students themselves. When asked how they stayed in touch with friends, girls primarily texted or used social media, saying that they did so at more or less the same rates as before. Male interviewees all indicated that since the shutdown, they have almost exclusively stayed in touch with their other guy friends through multiplayer online games, such as Fortnight. They all said that they do not make a habit of texting or do not otherwise use other peer-to-peer channels. However, they did indicate how much they missed playing sports with friends, seeing them in class, or riding bikes to school - apparently a "third place" (Oldenburg, 1989) that has just not been filled during the online transition. This may have posed several risks to their emotional wellbeing. As one teacher explained:

The kids are very used to being able to come into my class and be like, 'Oh, Ms. [Name Omitted], did you hear about this?' And then, they go into the thing that they heard about on the news, and then, we always have to have a discussion about it ...We always talked about current events, and I think that that helped a lot when they were going through things that were potentially really scary. A lot of kids really wanted to talk about what was going on especially immediately after George Floyd was murdered and then as they 
watched the protests. I did a Google Meet, and I had a few students show up, and they all just wanted to talk about how they felt impacted. I think that helped, but the only students that showed up were the ones that were very, very talkative in my class all the time, and it wasn't all my kids ... All I could think was I wish I was teaching [in-person] right now because I know my kids are terrified by this, and I can't be there to talk it through with them ... I was not able to make that a mandatory discussion. Everything besides the LiveLessons is asynchronous.

This sentiment illustrates that by design, simple and mindful gestures (and their ability to be done within a given delivery platform) can do much in the way to bolster wellbeing and the perception of learning quality. Furthermore, it reflects a need for students to connect with their teachers and peers to discuss their feelings in a reciprocally supportive environment.

\section{Conclusion}

The purpose of this study was to review College Park Academy's (CPA) transition from a hybrid learning model to fully online distance learning during the COVID19 pandemic. In the case of a pandemic, disruption to education may be long-term, requiring the response and recovery periods to overlap. This research worked to establish a snapshot of the school's underlying structure and disaster preparedness strategies, before evaluating the perceived viability and sustainability of the online model towards academic quality. Based on the lived experiences of school community members, it sought to understand what better enabled staff, faculty, students, and parents for successes with online learning, looking towards best practices and lessons learned to share with both CPA and the academic community at-large.

The REMS TA Four Components of Recovery framework served as the basis for development of interview and observation protocols. Within the Academics component specifically, the three dimensions of COI were embedded to address Cognitive, Teaching, and Social presence in the distance learning environment. The researchers conducted 17 interviews with administrators, teachers, support staff, parents, and students from across the school community. Additional observations included live and archived classroom instruction, as well as virtual Parent Teacher Association and Townhall meetings.

Ultimately, this study concludes that CPA's unique approach to hybrid learning lent itself towards both successes and failures in its transition to fully online delivery. The mix of in-person and online classes formerly offered, including the school's use of Pearson Connexus, provided a base level of preparedness for distance learning during the COVID-19 physical school closure, not necessarily paralleled by other schools. Although CPA administrators excelled in communicating with parents, staff, and teachers during this time, student wellbeing would have been bolstered by a more proactive approach in including them in the disaster response and recovery and ensuring communication with students directly, especially in terms of increased motivational messaging, grading policy updates, 
and information on counseling and other support services. During Spring 2020, the burden in many ways fell on students to reach out for support first with students themselves indicating isolation and strains on interpersonal relationships as a result. The push for additional in-service during Spring Break appears to have benefited CPA teachers and their comfort level with basic online instruction. However, for long-term viability and sustainability, there are several ways in which CPA should continue to improve the quality of the remote educational experience.

One of the key items missing in the online classes was teacher presence and student connection to other students, resulting in families having to assume the burden of lecture-based, self-directed learning. The lack of inquiry-based strategies and collaborative exercises challenges the depth of the learning exchange and its ability to foster the critical thinking skills needed for college-readiness. If multiple tools had already been integrated into Connexus, this may have alleviated some of the teachers' need to engage with other platforms or shoulder their reliance on lecture-only delivery. As it stands, findings reveal that students showed significant levels of frustration over course expectations, content delivery, participatory opportunities, and social isolation. By not defining these needs in the transition to fully online delivery, this led to a stated unwillingness by students to pursue other online education in the future and curtained the quality of the learning environment.

To this end, our recommendations include that it would be beneficial for educators to explore additional digital platforms and tools that would work to better facilitate wellness checks, provide human touchpoints, and target collaborative, studentcentered pedagogy. There also needs to be continued investment in training teachers on UDL, accessibility, and instructional strategies for the online classroom, as well as renewed focus on social emotional supports. This may involve finding ways to include more feedback channels for students, as well as opportunities to promote a sense of social presence within online and virtual spaces as is proposed in the COI Framework. This can include more training on how to create blended environments, particularly towards flipped classroom approaches and better technology integration. Lastly, student engagement in the disaster planning, response, and recovery would benefit the school community overall, motivate students in their own response, and help to strengthen their resilience.

Acknowledgments We thank Dr. Helene Kalson Cohen (University of Maryland, College Park) for her oversight and general support of the study, as well as Dr. Sarah C. K. Moore (University of Maryland, College Park) for her contributions to research design, data collection, and analysis.

Authors' contributions All authors contributed to the study conception, material preparation, data collection, and analysis. The first draft of the manuscript was written by Kate Maloney Williams, and all authors commented on previous versions of the manuscript. All authors read and approved the final manuscript.

Funding This study was funded by The Children's Guild.

Data availability Due to the nature of this research, participants of this study did not agree for their data to be shared publicly, so supporting data is not available.

Code availability Not applicable. 


\section{Declarations}

Ethics approval The research protocols used were approved by the ethics committee of the University of Maryland, College Park; College Park, MD, USA [UMD IRB Protocol \#1600036-1].

Consent to participate All participants provided written informed consent for their participation in the study. In the case of minors, informed assent was documented, as well as parental or guardian permissions. Forms shall be furnished to the Editor upon request.

Consent for publication Permission to publish has been granted by College Park Academy and the University of Maryland, College Park.

Conflicts of interest/Competing interests All authors certify that they have no affiliations with or involvement in any organization or entity with any financial interest or non-financial interest in the subject matter or materials discussed in this manuscript.

\section{References}

CAST. (2018). Universal design for learning guidelines. http://udlguidelines.cast.org. Accessed 2 Aug 2020.

Corbin, J., \& Strauss, A. (2015). Basics of qualitative research: Techniques and procedures for developing grounded theory (4th ed.). Sage.

Fischer, G. (2011). Understanding, Fostering, and Supporting Cultures of Participation. Interactions, $18(3), 42-53$.

Gaillard, J. C., Amirapu, T., Hore, K., \& Cadag, J. R. D. (2018). Child-centered research-into-action brief: Inclusion in disaster risk reduction. GADRRRES. https://www.preventionweb.net/files/ 61519_includingchildrenindrrr2abriefeng20.pdf. Accessed 10 Aug 2020.

Garrison, D. R., Anderson, T., \& Archer, W. (2000). Critical inquiry in a text-based environment: Computer conferencing in higher education model. The Internet and Higher Education, 2(2-3), 87-105.

Gauntlett, D. (2011). Making is connecting: The social meaning of creativity, from DIY and knitting to YouTube and Web 2.0. Polity Press.

Hall, E. T. (1976). Beyond culture. Anchor.

Hollingshead, A., \& Carr-Chellman, D. (2019). Engaging learners in online environments utilizing universal design for learning principles. eLearn Magazine. https://elearnmag.acm.org/featured.cfm? aid=3310383. Accessed 2 Aug 2020.

Hone, K. S., \& El Said, G. R. (2016). Exploring the factors affecting MOOC retention: A survey study. Computers \& Education, 98, 157-168.

Hyogo Framework. (2005). Hyogo framework for action 2005-2015: Building the resilience of nations and communities to disasters. United Nations International Strategy for Disaster Reduction. https:// www.unisdr.org/2005/wcdr/intergover/official-doc/L-docs/Hyogo-framework-for-action-english.pdf. Accessed 10 Aug 2020.

IIEP-UNESCO. (2020a). Coordinate, plan and communicate. COVID-19 Response Briefs. http://www. iiep.unesco.org/en/coordinate-plan-and-communicate. Accessed 10 Aug 2020.

IIEP-UNESCO. (2020b). Maintain operational capacities during school closures. COVID-19 Response Briefs. http://www.iiep.unesco.org/en/maintain-operational-capacities-during-school-closures. Accessed 10 Aug 2020.

IIEP-UNESCO. (2020c). Provide continuous support to teachers, learners and their families. COVID-19 Response Briefs. http://www.iiep.unesco.org/en/provide-continuous-support-teachers-learners-andtheir-families-13375. Accessed 10 Aug 2020.

INEE. (2020). Technical notes. Education during the COVID-19 pandemic. Version 1. https://inee.org/ system/files/resources/INEE\%20Technical\%20Note\%20on\%20COVID-19\%20EN\%202020-04-23. pdf. Accessed 10 Aug 2020. 
Lee, W. O., \& Tan, J. P. (2018). The new roles for twenty-first-century teachers. In H. Niemi, A. Toom, A. Kallioniemi, \& J. Lavonen (Eds.), The teacher's role in the changing globalizing world (pp. 11-31). Koninklijke Brill NV.

McLuhan, M. (1964). Understanding media: The extensions of man (2nd ed.). Mentor.

McWilliam, E. L. (2009). Teaching for creativity: From sage to guide to meddler. Asia Pacific Journal of Education, 29(3), 281-293.

Merriam, S. B. (2002). Qualitative research in practice: Examples for discussion and analysis. Jossey-Bass.

Oldenburg, R. (1989). The great good place: Cafes, coffee shops, centers, beauty parlors, general stores, bars, hangouts, and how they get you through the day. Paragon House.

Quebral, N. (1988). Development communication. UPLB College of Agriculture.

REMS TA Center. (2006). School responds to infectious disease. Emergency Response and Crisis Management (ERCM) Technical Assistance Center. U.S. Department of Education. ERCM Express. 2(7). https://rems.ed.gov/docs/PandemicFluNewsletter_072106.pdf. Accessed 10 Aug 2020.

Reyes, J. (2013). What matters most for education resilience: A framework paper. SABER Working Paper Series, Number 7. World Bank Group.

Sendai Framework. (2015). Sendai Framework for Disaster Risk Reduction 2015 - 2030. United Nations Office for Disaster Risk Reduction. https://www.preventionweb.net/files/43291_sendaiframework fordrren.pdf. Accessed 10 Aug 2020.

Sternberg, J. (2012). Misbehavior in cyber places: The regulation of online conduct in virtual communities on the internet. UP of America.

UNHCR. (2016a). Global Trends: Forced Displacement in 2015. https://www.unhcr.org/statistics/unhcr stats/576408cd7/unhcr-global-trends-2015.html. Accessed 10 Aug 2020.

UNHCR. (2016b). Missing Out. Refugee Education in Crisis. https:/www.unhcr.org/enus/news/press/ 2016/9/57d7d6f34/unhcr-reports-crisis-refugee-education.html. Accessed 10 Aug 2020.

Unwin, T. (2009). Development agendas and the place of ICTs. In T. Unwin (Ed.), ICT4D: Information and Communication Technology for Development (pp. 7-38). Cambridge UP.

U.S. Department of Education. (2010). Evaluation of Evidence-Based Practices in Online Learning. www.ed.gov/about/offices/list/opepd/ppss/reports.html. Accessed 2 Aug 2020.

Winthrop, R., \& Matsui, E. (2013). A new agenda for education in fragile states. Center for Universal Education Working Paper 10. Brookings Institute.

Publisher's note Springer Nature remains neutral with regard to jurisdictional claims in published maps and institutional affiliations. 